\title{
Mentoring in Medicine (MIM): Motivating and Enabling Disadvantaged Youth to Become the Next Generation of Minority Health Professionals
}

\author{
Lynne M. HOLDEN M.D. ${ }^{1}$ \\ Albert Einstein College of Medicine and Mentoring in Medicine. Inc., New York, N.Y. \\ U.S.A.
}

\begin{abstract}
Mentoring in Medicine, Inc (MIM) is a nonprofit health and science youth development organization based in the Bronx, NY. Founded in 2006 by three physicians and an engineer- trained entrepreneur, MIM's organizational goal is to expose socioeconomically disadvantaged students to the wide variety of health and science careers and to increase the health literacy of their communities. It is aligned with the outreach mission of the U.S. National Library of Medicine (NLM) whose former Director, Donald A.B. Lindberg M.D., fostered an enduring relationship. Technical assistance, evaluation, and financial support provided under his leadership helped MIM to become a nationally recognized organization leading the field to diversify health careers and to increase health literacy in often hard to reach populations. Through live and virtual programming, MIM has impacted nearly 58,000 students, parents, and educators in urban epicenters in the U.S. The MIM Team has helped 503 students who were discouraged to build a competitive application and matriculate in health professional school. MIM has 88 press features highlighting its work in the community.
\end{abstract}

Keywords. U.S. National Library of Medicine, Donald A.B Lindberg M.D., Mentoring in Medicine, health and science careers, disadvantaged youth, health disparities, outreach.

In memory of Donald West King M.D., 1927-2018

Deputy Director for Research and Education, U.S. National Library of Medicine

\section{Introduction}

Mentoring in Medicine, Inc. (MIM) is a 501c3 health and science youth development organization based in the Bronx, NY. It was founded in 2006 by three physicians Lynne M. Holden, M.D., Yvette Calderon, M.D., Jocelyn Freeman-Garrick, M.D. and an engineer-trained entrepreneur, Andrew Morrison. The purpose of MIM is to expose socioeconomically disadvantaged students to the breadth of health and science careers, in addition to promoting health literacy in communities in need. MIM is aligned with the

\footnotetext{
${ }^{1}$ Corresponding author: Lynne M. Holden M.D., Executive Director, Mentoring in Medicine Inc., E-mail: holden@medicalmentor.org
} 
outreach goals of the U.S. National Library of Medicine NLM), as co-featured by the NIH MedlinePlus Magazine [1].

The mission of MIM is to inspire, educate, expose, and empower young people to pursue their goal of becoming a healthcare professional and adopt a role as a community health ambassador. (See Photo 1.) It is a unique continuity program, the target audience is made up of students from elementary school to health professional school, along with parents and educators. The goal of MIM is to broaden the diversity of the biomedical workforce and to reduce disparities in health care. Using academic enrichment, leadership development, civic engagement, and mentoring, MIM helps students develop the knowledge, attitudes and skills needed to succeed.

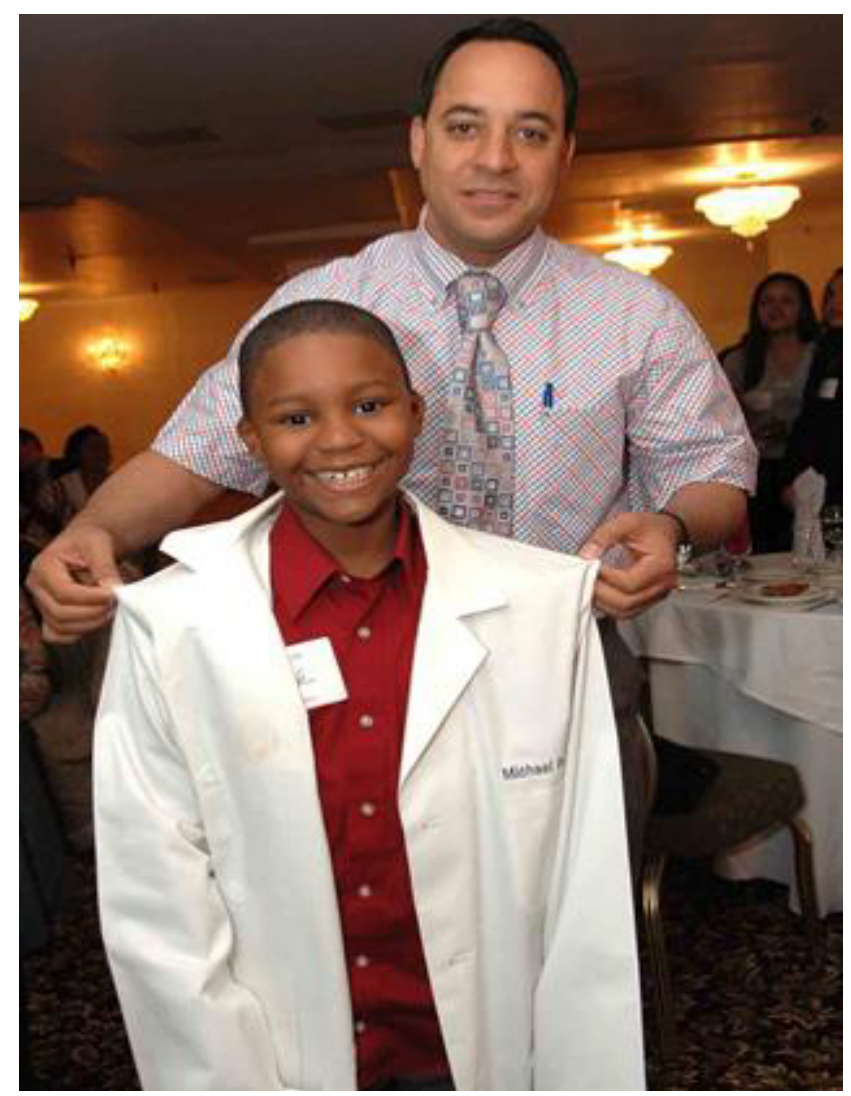

Photo 1. At a Mentoring in Medicine event, a possible future healthcare professional gets the chance to model a lab coat with a MIM mentor.

\subsection{The Challenge}

Mentoring in Medicine was conceived to increase the diversity of health and science careers by expanding the pool of competitive applicants targeting disadvantaged populations in which representation is historically very low. Each of the co-founders had a uniquely difficult path to becoming a physician. However, in making the path easier for young people, it was realized there would be many challenges to the work. Many students are first generation college or even high school graduates not aware of the 
journey to a health career. Other students suffer from adverse childhood experiences such as food insecurity, homelessness, and financial instability. Most must work while attending high school or college. Additionally, many students have attended underresourced middle and high schools without opportunities for academic enrichment necessary to build a strong foundation. Other real obstacles to the program included the creation of culturally appropriate and exciting content to capture the attention of the students to keep them engaged at the middle and high school level.

\section{A Pivotal Point for MIM}

In 2007, Lynne Holden M.D. and David Nash, Equal Opportunity Officer at the National Library of Medicine (NLM), met during a networking event at the National Medical Association's Annual Conference in Hawaii. Mr. Nash introduced Donald West King, M.D., who served as the Deputy Director of Research and Education at NLM, to Mentoring in Medicine, Inc. during a clinical skills workshop for medical students at the concurrently held Student National Medical Association Conference. Even though he was observing the MIM workshop for medical students, Dr. King jumped right in and began explaining the physiology of the heart during the EKG workshop. He also put on a pair of gloves and began to point out the anatomy of the pig's heart and explain the physiology of the human heart. The MIM Team had no idea that he had been the Chair of Pathology at the University of Colorado, the University of Chicago and Columbia School of Physicians and Surgeons. But they knew that he was an ally!

\section{A Breakthrough with the National Library of Medicine}

Dr. King referred Dr. Holden to Donald A.B. Lindberg M.D. NLM Director, who after a lengthy competitive vetting process enthusiastically encouraged MIM to collaborate with the American Dental Education Association (ADEA) on a new outreach project that would combine their respective interests in promoting health careers for students. The leaders of both organizations decided to work together on a mutually beneficial effort that would further inform their individual causes. They decided to perform two focus groups in NYC about the perceived obstacles to a health career among urban students, parents, and educators, to learn strategies to effectively promote health careers and to demonstrate a new ADEA online platform. Representatives of both organizations worked together to host the first event over dinner at The New York Academy of Medicine and the second a month later over lunch at Frederick Douglass Academy I in Harlem. Subsequently, a manuscript documented the results that informed the work of MIM [2]. In fact, hosting the focus groups launched one key practice in MIM's success over the years which has been to query the target audience before designing and implementing a program. Therefore, the motto," not me without me" drives the creation of any new MIIM program. Changing norms requires constant surveying of the target population to make sure that their needs are met in an effective manner.

The focus groups yielded important results. The inclusion of parents as key participants in the group was unusual. In total, there were six focus groups studied: with a total of 45 persons in the first session, and 10 persons in each of the second session groups. There were surprising differences between the knowledge, attitude and beliefs 
of the students, parents, and educators. Based on the results of the focus group, a clear case was made for the need to introduce students in middle and high school to a variety of health careers so they could be academically competitive, develop social identity and participate in experiential learning opportunities. The strong lack of confidence to pursue health careers that was expressed at multiple educational levels was disheartening but gave the MIM Team clear direction that programs needed to incorporate a growth mindset with engaging activities and clear incentives for excellent performance.

\section{Building the Relationship with the National Library of Medicine}

Annually, for ten years, MIM hosted a large celebration of health careers. Typically, up to 2,500 students, parents, and educators along with nearly 200 health professionals and health professional students would participate in a day-long Saturday immersion experience showcasing a variety of health careers through pep rallies, hands-on activities, and workshops. Dr. and Mrs. Lindberg traveled to NYC in 2008 and attended the "Yes, I Can be a Healthcare Professional!" Conference in Harlem, New York at the Frederick Douglass Academy I (See Photo 2). After walking around the Exhibit Hall and speaking to students in the New York after school program as they presented health career posters, Dr. Lindberg became an advocate! Once they returned to Bethesda, Dr. Lindberg and Dr. King led the capacity building and replication effort of Mentoring in Medicine together.

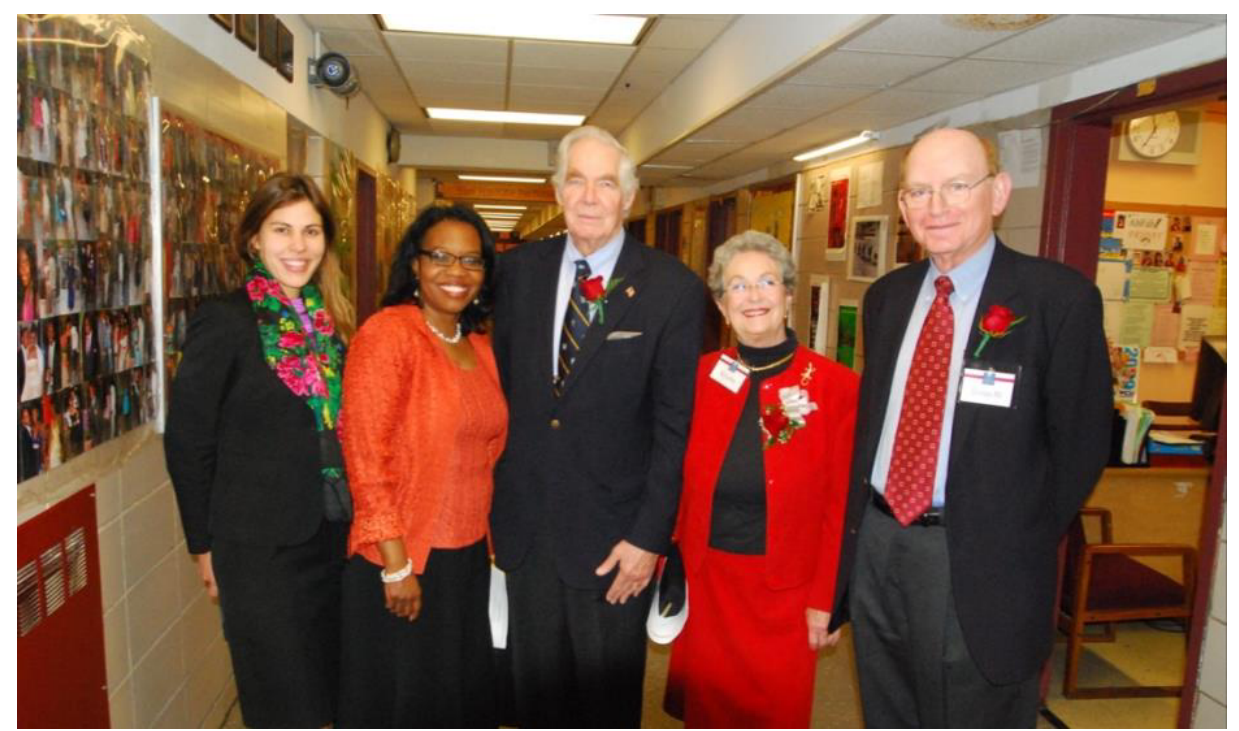

Photo 2. Dr. Holden with Dr. and Mrs. Lindberg, center, at the 2008 MIM Conference, "Yes, I Can Be a Healthcare Professional!"

With this new NLM connection, Dr. Holden as MIM president, was invited to join the Board of Directors of the Friends of the National Library of Medicine (FNLM) in 
2009. This nonprofit organization supports the mission and strategic plan of the NLM. Under the chairmanship of Dr. King, the FNLM adopted MIM as an outreach arm. Through collaborative projects, MIM strives to increase the workforce diversity by building data literacy and encouraging healthy living in our programs for students from middle school to health professional school.

\subsection{The NLM Outreach Team}

After his first experience in Harlem, Dr. Lindberg expressed his growing enthusiasm for the work of MIM. He was able to envision the possibilities of the then fledgling nonprofit organization. He invested his resources at the NLM, the world's largest medical library, to help multiply the impact of MIM on the world. What a one in a million chance for an early nonprofit to receive such a gift! Dr. Lindberg developed an Outreach Team to assist with MIM Programs through technical assistance, evaluation, replication, and fund development. The Team consisted of: Patricia Carson, executive assistant to Dr. Lindberg; Elliot R. Siegel Ph.D., Associate Director; George Franklin, outreach leader; and David Nash. Later, Wallace G. Berger, PhD. LightShift Associates, LLC, joined the team as an evaluation consultant. Dr. Lindberg charged Dr. King with leading the direction of the Outreach Team.

\section{The Growth of MIM}

A key factor in the growth of MIM was the technical assistance provided by the Outreach Team. Dr. King invited Dr. Holden and the MIM leadership team to his home in Riverdale to assist with the middle and high school program development to incorporate pathobiology, a term that Dr. King coined, in 1967 when he co-founded the Givens Institute of Pathology in Aspen, Colorado. The weekly technical assistance sessions occurred every Wednesday evening after the family (and friends) dinner for 11 years. These sessions led to the development of the first Anatomy, Physiology, Pathology and Biomedical Careers Elective in NYC high schools, an after-school program (ASP) for middle school students, and a summer camp for middle and high school students [3]. The MIM school-based programs incorporated engaging project-based learning using NLM information resources such as the NIH Medline Plus Magazine, the MedlinePlus consumer health website, and the PubMed biomedical literature citation database.

\subsection{After-School Program}

The MIM After-School Program (ASP) has as its primary objective to provide academic enrichment in human biology and to motivate disadvantaged youth to pursue a career in the health professions. Secondary objectives are to improve students' health literacy and knowledge of healthy living behaviors. A qualitative and quantitative study was performed on the ASP in six schools with 84 students in 9th-12th grades who completed the 10-week semester [4]. Students across the academic spectrum appeared to have learned the MIM ASP Course content - high school GPA was not a predictor of knowledge acquisition. The students also reported that the ASP Course significantly increased their self-confidence in their ability to succeed (self-efficacy). The students expressed a significant increase in five health care related attitudes and an additional 
increase in their ability to overcome personal issues to succeed in their career and significantly improving their feeling toward, and likely pursuit of, a health career. The students stated that the ASP Course significantly increased their interest and intent to seek out more information about health care, participate in health care activities, and take more health care courses in high school. The qualitative evaluation found that the students and their parents were pleased with the MIM ASP Course's composition, presentation, and effectiveness. With a large majority of the parents stating that their child got out of the ASP Course what they had hoped for and that the ASP Course made it more likely that they would recommend a health career for their child. The students and instructional staff also identified the ASP Course elements that they felt were most and least effective.

\subsection{Student Posters Encouraging Health Careers}

Dr. and Mrs. Lindberg attended the "Yes, I Can be a Healthcare Professional!" Conference for five years straight at the Frederick Douglass Academy I in Harlem with the number of participants from the community ballooning to nearly 3,000 attendees. Meanwhile, the number of NYC participating schools grew to ten and, as one of their capstone projects, the students were charged with creating posters about health careers and/or diseases. After the first semester of the program, the culminating event for students to showcase their projects for the broader community was at the "Yes, I Can be a Healthcare Professional!" Conference. As the number of school-based programs increased, the number of middle and high student poster presentations greatly expanded. Students were expected to dress professionally as they stood beside their poster and presented the information. Conference participants were asked to grade each poster to choose a slate of prize winners in the middle and high school categories. Every year, Dr. Lindberg enjoyed engaging the students and examining their posters. That section of the conference was renamed the Dr. Donald A.B. Lindberg Exhibit Row to honor his wisdom and guidance in support of the MIM students.

After each conference, students from the program were invited to have lunch with Dr. Lindberg. He would participate in a lively exchange about a variety of topics to the amusement of the middle and high school students and their parents. Teachers from the various schools also attended the Saturday event with their students. Mrs. Lindberg actively participated as she shared her experience as a registered nurse. More importantly, both Dr. and Mrs. Lindberg strongly encouraged the students to pursue their dreams and that a health career and improving the health of their communities was very much needed--and possible for them to achieve.

\subsection{Virtual Summer Science Camp}

Nearly a decade before the reliance on virtual instruction to educate students during the COVID-19 pandemic of 2020, MIM became a leader in teaching urban students advanced scientific concepts and healthy living using NLM resources during the summer using synchronous e-learning. Created and implemented in 2012, the Virtual Summer Science Camp (VSC) utilized a hybrid method of instruction with "live" student audience and the virtual audience would engage with "live" speakers and activities. The Mentoring in Medicine Team was able to provide a novel meaningful project-based learning experience for students internationally beginning in middle school as demonstrated through formal evaluation of the summer of July 2012 in which the Cardiovascular 
System was taught [5]. First, students explored a variety of careers in the health professions. Next, participants increased their information seeking behaviors about health. Students improved their health literacy and understanding of health disparity issues. They improved their test-taking and study skills. Finally, the participants understood advanced biological concepts and diseases affecting the cardiovascular system which was the subject matter of this initial VSC offering.

\subsection{Community Health Ambassadors Program}

In order to engage post-secondary school students on the journey to becoming a biomedical professional, the MIM Team launched the Community Health Ambassador Program (CHAMP) in 2007. College and post-baccalaureate students participated in a year-long academic enrichment, community service and mentoring experience. Students participated in outreach programs with MIM partners such as community-based organizations, churches, and food kitchens. In 2009, Dr. Holden was one of ten nationally recognized Robert Wood Johnson Community Health Leaders for creation and implementation of CHAMP.

During the 2009 Swine Flu pandemic, CHAMP students stood outside busy subway stations in Harlem and the South Bronx with health professional volunteers handing out bilingual NYC Department of Health information. In 2012, MIM partnered with the Icahn School of Medicine at Mount Sinai to help disseminate health messages in Harlem. Throughout a span of twelve months and 54 events, twenty-five Ambassadors were able to disseminate over 8,000 health messages to the East and Central Harlem communities.

CHAMP expanded to the high school level becoming an integral part of the inschool elective in 2018 allowing students to perform community service and improve health literacy in their school and local community. Examples of student projects included creating and displaying posters during lunch in the cafeteria describing influenza prevention and protection methods. Such activities are essential to empower the MIM students and to increase health literacy among their peers.

\section{Replicating the MIM Programming}

Dr. Lindberg received regular reports from the Outreach Team about the growth and progress of MIM. He was pleased with the reports and nicknamed Dr. Holden "the spark plug." Under his guidance, the MIM and NLM Outreach Teams created, implemented, evaluated and utilized the lessons learned to replicate the programs to a growing audience.

In 2012, at the urging of Mrs. Lindberg, Dr. Lindberg helped Mentoring in Medicine to establish the ASP in Washington, DC in Wards 7 and 8 which were especially adversely affected by health differences. This significant turning point was a huge leap for Mentoring in Medicine. The expansion and replication of services meant expanding the team and developing partnerships with schools, hospitals, and medical societies. Since Dr. Holden graduated from Howard University, she was able to build a network of health professionals, college student instructors and school contacts to implement the ASP in up to six middle and high schools. MIM also leveraged additional funding sources to sustain and grow the number of schools participating. 


\subsection{Science Day at the National Institutes of Health}

Dr. Lindberg also helped to replicate the Harlem Fair focusing instead on science on the campus of the National Institutes of Health (NIH). In 2014, a large event to expose students to biomedical science was launched. The Science Day for Students at NIH has been co-sponsored by the National Library of Medicine and the National Institute on Minority Health and Health Disparities and held for seven years with over 3,000 DC area minority students and up to $20 \mathrm{NIH}$ Institutes participating [6-8]. In 2021, due to the COVD 19 pandemic, the event expanded virtually allowing the MIM NYC schools to also participate.

\section{Lessons Learned}

Using the qualitative research methodology of focus groups allowed MIM to develop insight and direction before designing and implementing the school-based programs. MIM programming incorporates important elements that can serve as best practices for other health career-oriented educational interventions with underrepresented minority students in urban settings: (a) Know and understand all aspects your target population, including their attitudes, beliefs, and concerns; (b) Address disincentives, such as family financial limitations, peer pressures, and the lack of positive role models; (c) Develop programming that is comprehensive, long-term, and participatory; (d) Develop programming that is age and grade appropriate, encompassing and reinforcing the journey that students make from middle school to high school, through community and four year college, and enrollment by some in graduate professional school; (e) Venture outside the traditional classroom to offer after school courses, and experiment with information and computer technologies that support interactive virtual learning; and (f) Provide individual and group mentoring whenever possible, including exercises that build self-confidence, promote social and emotional skills strengthening, and enhance study and test-taking skills. In consistent independent evaluations, it was found that the lower performing student in school excelled in the Mentoring in Medicine program. This was good news to try to capture those students with great potential!

Building upon the initial focus groups, MIM designed school-based courses that capture student interest, foster motivation/engagement, impart knowledge/skills, and change attitudes thus building student confidence in their capability to succeed while being relevant to their economic, social, community, and cultural backgrounds. In addition to teaching the anatomy, physiology, and pathology, the MIM school-based course has several unique features which include growth mindset instruction through an equity lens addressing health care disparity issues and social determinants of health affecting the students' communities. The courses infuse youth culture (e.g., use of animated and video materials, rap and spoken word in projects) and current events into the curriculum increasing the interest and participation of the students. It helps increase the curiosity for learning by understanding the students' conceptual framework. The students are motivated by culturally relevant role models who visited the classroom and discuss their journey to a healthcare career and their strategies for success. The handson activities appeal to the multimodal learner. (See Photo 3.) Parents are involved in the program (e.g., pre and post surveys, newsletters), thus creating partnerships with the students' key career influencers. The MIM team provides a low risk, safe academic 
environment which encourages students to participate in classroom activities as individuals and as part of small groups (e.g., classroom games - Jeopardy).

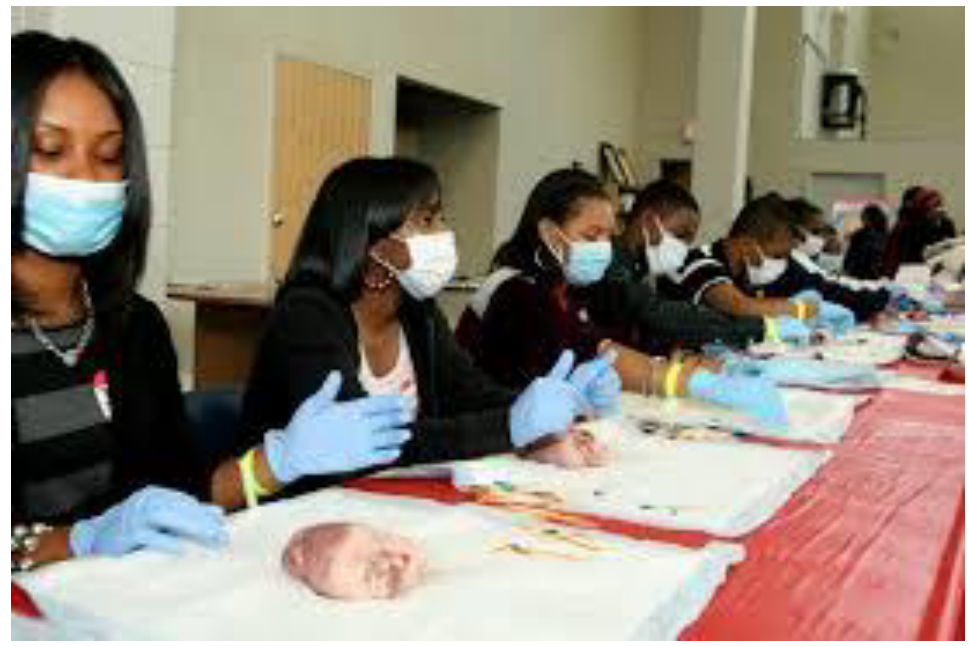

Photo 3. At a MIM workshop, students learn about how to dissect pig hearts, under the guidance of medical professionals.

\section{Conclusion}

The growth of Mentoring in Medicine is attributable in no small measure to the support and direction of Dr. Donald Lindberg and his Outreach Team; especially the late Dr. Donald King who united the organizations and enabled the MIM Team to make a tremendous impact on the lives of so many students. MIM programs grew from NYC then expanded to Washington, DC and nationally. MIM became an innovative educator of students at all grade levels, thus, building a continuity of programming with live, interactive, and virtual capabilities. MIM has impacted nearly 58,000 students, parents, and educators in the U.S. MIM has helped 503 students who were discouraged to build a competitive application and matriculate in health professional school. MIM has 88 press features highlighting our work in the community. MIM has become a national organization known for cultivating and grooming students beginning in elementary school, who are underrepresented in the fields of health care and health sciences.

\section{References}

[1] Mentoring in Medicine program encourages careers in health. NIH Medline Plus Magazine. [Internet] Summer 2011, Volume 6. Number 2. [cited 2021 July 13] p. 22-3. Available from: https://magazine.medlineplus.gov/pdf/MLP_Summer_2011.pdf.

[2] Holden L, Rumala B, Carson P, Siegel E. Promoting careers in health care for urban youth: What students, parents and educators can teach us. Inf Serv Use. 2014 Jan 1;34(3-4):355-366. DOI: 10.3233/ISU140761. PMID: 25580044; PMCID: PMC4286884.

[3] Building paths to health careers. NIH Medline Plus Magazine. [Internet] Spring 2012, Volume 7. Number 1. [cited 2021July 13] Inside front cover. Available from: https://magazine.medlineplus.gov/pdf/MLP_Spring_12.pdf 
[4] Holden L, Berger W, Zingarelli R, Siegel E. After-school program for urban youth: evaluation of a health careers course in New York City high schools. Inf Serv Use. 2015;35(1-2):141-160. DOI: 10.3233/ISU150773. PMID: 26316659; PMCID: PMC454897

[5] Holden L, Morrison A, Berger W, Siegel E. E-learning in a virtual science camp for urban youth. Inf Serv Use. 2013;33(3-4):299-308. DOI: 10.3233/ISU-130718. PMID: 24733956; PMCID: PMC3984542.

[6] Newton R. Science day at NIH seeks to empower students. NIH Record. [Internet] May 19, 2017. Vol. LXIX, No. 10. [cited 2021 July 13]. p. 9. https://nihrecord.nih.gov/sites/recordNIH/files/pdf/2017/NIHRecord-2017-05-19.pdf

[7] Newton R. Inspiring next generation researchers: 5th Science Day at NIH invokes energy, passion. NIH Record. [Internet] June 29, 2018. Vol. LXX, No. 13. [cited 2021 July 13]. p. 7. https://nihrecord.nih.gov/2018/06/29/5th-science-day-nih-invokes-energy-passion

[8] Patel J. Science Day inspires next generation of researchers. NIH Record. [Internet] January 10, 2020.Vol. LXXII, No. 1. [cited 2021 July 13]. p.10. https://nihrecord.nih.gov/2020/01/10/science-dayinspires-next-generation-researchers 